\title{
INDIGENOUS HEALERS IN THE NORTH WEST PROVINCE: A SURVEY OF THEIR CLINICAL ACTIVITIES IN HEALTH CARE IN THE RURAL AREAS
}

\author{
SN Shai-Mahoko
}

\begin{abstract}
The purpose of this study was to explore the clinical conditions brought to indigenous healers by people in the rural areas in search of health care. The demographic variables and preventive, promotive, curative and follow-up activities of indigenous healers were investigated. Data were collected from a simple random sample of 35 indigenous healers. A questionnaire designed by Mogoba (1984) for investigation of training and functioning of traditional doctors in Southern Africa was modified and used 10 collect data.
\end{abstract}

Findings showed that indigenous healers deal with the same health problems confronting formal healsh workers, especially in the paediatric field. Infertility, mental illness problems and sexually transmitted diseases ranked high in the adult conditions brought to the healers. There seem to be conditions that can be handled only by the indigenous healers due to their cultural nature. Findings also show that the services of indigenous healers are not conifined to any specific group or social class within black popularion.

\section{INTRODUCTION}

Observation made throughout the years of practice as a registered nurse revealed that most black patients presenting at health facilities have a scarification made by an indigenous healer on their bodies. Beads, robes, pieces of hides, bones and other charms are a familiar scene to those involved in the care of black South Africans

With South Africa's new health dispensation necessitating the working together of both the indigenous healer and the formal health worker, it is important to know the clinical conditions normally taken by the communities to the indigenous healers. We cannot expect cooperation when no one knows what the indigenous healers can and cannot handle.

There are indications that the African indigenous healer has been rejected by South African medical practitioners who were trained according to the westerm models (Gumede 1990). He is often regarded as a witch-doctor, a purveyor of superstition and a medical hazard. Much of this negative attitude became evident in 1994 during the processes of discussion forums for health policy formulation and reconstruction in the North West Province. There is, however, evidence that $80 \%$ of patients visit indigenous healers before they come to the hospital (Gumede, 1990). Despite this evidence, there is still denial by the health team that indigenous healers are involved actively in the provision of health care at community level. This attitude makes one question the reality and pragmatism behind the slogan "Health for all by the year 2000" given the unequal distribution of resources in the country.

While most formal medical practitioners condemn the services of the indigenous healers on the grounds that the scientific basis for traditional medicine has not been established (Khumalo, 1988; Koumare, 1983) it has been established that indigenous medicine caters for at least $80 \%$ of the African population (Koumare, 1983). Nemec (1980) states that two thirds of the people in the world today depend on the healing methods used by their ancestors, and in some areas it is the only type of health care available and with which people feel comfortable. Van Rensburg and Mans (1982) indicate the sharp contrast which exists between indigenous and western medicine in South Africa, but whether these two systems oppose or supplement each other, traditional healing practice is well established and popular among the black population.

Staugard (1985) acknowledges the existence of traditional medicine in all cultures as an independent health care system alongside the officially established health system but does not mention the activities performed by indigenous healers within these cultures.

\section{PURPOSE OF STUDY}

Since the situation demands that health workers should cooperate with indigenous healers in the provision of health services, the purpose of this study was to explore the views of the indigenous healers in relation to their job, and to identify the clinical conditions which are brought to them. This may provide an indication of the possible areas of co-operation between formal health worker and indigenous healer.

The study is considered significant of conditions in that literature does not indicate the existence of a similar study in the province. This study was an attempt to find common ground for cooperation and health education for the practitioners of both health systems. It will also form a preliminary study for determining the role that indigenous healers play in the health care of rural South Africans in terms of prevention of diseases and promotion of health in the future.

The assumption was that indigenous healers are confronted with the same diseases that the formal health workers are faced with; and that in the care of perceived treatment failure, the indigenous healers refer their patients to the formal health workers.

\section{OBJECTIVES}

Objectives of the study were to identify the conditions that the indigenous healers treat: determine whether there is any follow-up mechanism in place for their clients; find out the category of people who seek their services the most; and find out any existing liaison and coordination between the healers and the formal health workers.

\section{RESEARCH METHOD}

The study was an exploratory descriptive survey. Only indigenous healers in Thaba Nchu, Ganyesa, Kurumane, Mankwe and Molopo regions of the North West province were the population. Out of a list of sixty villages. 40 were drawn by simple random sampling using a sampling frame. A total of 35 indigenous healers was obtained from the headmen of the 40 villages. All 35 (100\%) were included in the sample and interviewed. 
TABLE 1: PAEDIATRIC DISEASE TREATED BY

INDIGENOUS HEALERS

\begin{tabular}{|lrr|} 
Condition & $\begin{array}{r}\text { No. of } \\
\text { respondents }\end{array}$ & $\%$ \\
Thogwana & 35 & 100 \\
Ditantanyane & 33 & 94 \\
Measles & 31 & 88 \\
Kwashiorkor & 28 & 80 \\
Whooping cough & 24 & 68 \\
\hline
\end{tabular}

The questionnaire used by Mogoba (1984) was modified and adopted. A structured interview schedule was developed in English and then translated into Setswana to facilitate the same understanding of meaning and content. The exercise was necessary since not all indigenous healers could read and write. Questionnaires were delivered by hand by students who were undertaking the Bachelor of Nursing Science degree at the University of the North West. Since the students residered in these areas, they acted as research assistants. A letter was written to all the subjects reassuring them of confidentiality.

\section{FINDINGS}

The first section dealt with demographic information. This included population group, age, gender, educational level and marital stanus. The most of the respondents $(60 \%)$ were Botswana. The remainder (40\%) belonged to other population groups.

More than half $(51 \%)$ of the healers were females. Thirty $(85,7 \%)$ were aged between 30 and 59 years old. This suggests that indigenous healing is undertaken by mature adults. Most (77\%) were married, and 5.7\% were divorced. The majority of the healers were not educated. Only $31 \%$ attained lower primary education; $25.7 \%$ finished high primary schooling and $22.4 \%$ never attended school.

\section{HEALING PRACTICES}

Information included the category of healer, training and registration, the type of diseases treated, diagnostic tools used, the referral system and the category of clients who visit the healers.

\section{TYPE of HEALER and TRAINING}

More than half $(60 \%)$ of the respondents practised as bone throwers, and over a quarter (34.2\%) practised as both bone throwers and sangomas. More than half (54\%) claimed to have been taught the art of healing by their ancestors through dreams. Some (31\%) went through formal training in indigenous healing. Fourteen percent were trained through apprenticeship by an experienced healer. Bone throwing appeared to be a common method used by the majority of healers (77\%)for the diagnosis of health problems. The period of training for the majority $(94 \%)$ of the participants ranged between 2 and 5 years. Of the 35 participants, $57 \%$ were registered with an association for indigenous healers.

\section{HEALTH PROBLEMS}

The conditions with which the indigenous healers are faced with are listed in Tables 1 and 2.

\begin{tabular}{|lrc|}
\hline \multicolumn{3}{|c|}{ TABLE 2: ADULT CONDITIONS } \\
TAKEN TO THE INDIGENOUS \\
HEALERS \\
Condition & $\begin{array}{r}\text { No. of } \\
\text { respondents }\end{array}$ & $\%$ \\
Infertility & 32 & 91 \\
Septic sores & 31 & 89 \\
Impotence & 30 & 86 \\
STDs & 28 & 80 \\
Deliveries & 26 & 80 \\
Makgome/Boswagade & 25 & 71 \\
Asthma & 23 & 66 \\
Mental illness & 21 & 60 \\
High blood pressure & 20 & 57 \\
Palpations & 15 & 43 \\
TB & 14 & 40 \\
Alcohollsm & 12 & 34 \\
Diabetes & 9 & 26 \\
Cancer & 9 & 26 \\
\hline & & \\
\hline
\end{tabular}

Treatment methods included oral medications (27, scarification (26), enemata (25), induced vomiting (26), ritual performance (26), preventing witchcraft (15). Other methods of treatment included those used by the Chinese, coloured and the Damara.

\section{TABLE 3: INDIGENOUS HEALERS' METHODS OF DISEASE PREVENTION AND HEALTH PROMOTION}

\begin{tabular}{|lrr|}
\hline METHOD & \multicolumn{1}{c}{ NO. } & $\%$ \\
$\begin{array}{l}\text { OO thaya motse } \\
\text { (Home fortifying) }\end{array}$ & 28 & 80 \\
$\begin{array}{l}\text { Go thapisa motse } \\
\text { (Home cleansing) }\end{array}$ & 28 & 80 \\
$\begin{array}{l}\text { Gothapisa batho } \\
\text { (cleansing persons) }\end{array}$ & 27 & 77 \\
$\begin{array}{l}\text { Scarification } \\
\text { Cultural education } \\
\text { (taboos, maphakwana) }\end{array}$ & 24 & 68.5 \\
\hline
\end{tabular}

Of the 35 participants, 26 (74\%) mentioned they refer their patients. Of these, 17 specified referral to the western trained physician and
12 specified referral to other healers. All (199\%) participants were generalists, and treated patients of all ages and sexes. Special emphasis was placed on the prevention and treatment of paediatric conditions and impotence.

All participants indicated that their clients retum for review and follow-up, and for the presentation of new health problems.

The results also showed that the indigenous healers are consulted by a variety of groups of people (see Table 4).

\begin{tabular}{lrr}
\multicolumn{3}{c}{ TABLE 4: CATEGORIES OF PEOPLE } \\
WHO CONSULT INDIGENOUR \\
HEALERS \\
Category & $\begin{array}{r}\text { No of } \\
\text { healers }\end{array}$ & $\%$ \\
Teachers & 32 & 91 \\
Nurses & 30 & 85.7 \\
Traders & 29 & 82.8 \\
Ministers of Religion & 26 & 74 \\
Police & 22 & 62.8 \\
Other & 22 & 62.8
\end{tabular}

\section{DISCUSSION}

The indigenous healers seem to be making a vital contribution to community health care services in spite of their low level of education. The $60 \%$ Batswana healers who participated indicates that the area where the study was conducted was mainly populated by that ethnic group. The findings are discussed in relation to the people in North West Province.

It is interesting to note that despite the healers' low levels of education, professionals such as teachers, nurses and ministers of religion use the services of indigenous healers. Two explanations are possible. The one is that education and/or a profession does not divorce one from one's cultural orientation. The other is that indigenous healers have something to offer that formal health services do not have.

On-the-job training forms an important aspect of indigenous healing. This form of training is also part and parcel of the nurse's work life in the provision of health care, so that the intern can pick up by observation and instruction his knowledge and skill (Bryant, 1983:10).It is evident that registration of healers is not considered a top priority for the practice of healing in the North West Province. This needs serious consideration for the following reason. In as much as there are good healers, there are also those who pollute the traditional medical field. Unless there is a well-kept register for the indigenous healers, it will be difficult to differentiate healers from quacks. 
Looking at the findings, it is a pity that the formal health services in the region still ignore the existence and utilization of the services of indigenous healers in the community. They are in abundance, and are actively involved in providing health care to different cultural groups. Although they have a different strategy for determining a health problem, the objective is the same as for those trained according to a western model; that is, to provide health care to the people. This purpose should be the only important indication for cooperation. This is the reason for the formal health worker to do away with professional pride, and work closely with the indigenous healer to provide health care that is congruen with the culture of the people being served.

African indigenous healers seem to be confronted with the same conditions that the formal health practitioners are faced with and Tables 1 and 2 show a list of diseases typically found among the disadvantaged communities. It is common knowledge among the South African Blacks that children are taken to indigenous child specialists after birth for prevention of certain childhood diseases such as "phogwana"(diarrhoea and vomiting). "thema" (red spots at occipital region suggestive of a potential condition similar to meningitis) and "methlhala" (dangerous tracks of infected people, especially the widowed and those who have aborted). The findings support statements of Rappaport and Rappapor (1981) and Edwards (1986) the whereas the western trained practitioners look at the signs and symptoms of the disease, the indigenous healers look at the cause. Whether or not medical science believes in the cause as perceived by the indigenous healer, the fact is that children are taken to the healer for treatment. If it works for the users of indigenous healers' services, the people need to be encouraged to use whatever means possible to attain and maintain health. The indigenous healers also need to be encouraged in referral of those who are not satisfied with their services, or where there are no indications for improvement within a specific time. Such a cooperative move would save lives and cut down on prolonged periods of illness.

Psychiatric conditions are difficult to cure, yet $60 \%$ of the participants reported that they have treated patients successfully suffering from mental illness. These findings are supported by other authors (Ademuwagun 1976; Lambo 1973) who state that traditional healers can treat mental illness successfully. In support, medical practitioners such as Mogoba (1984) state that mental illness is better treated by traditional healers. It is also worth noting that although no research has been conducted in the North West Province, a lot of discharged psychiatric patients have been lost and traced to the services of indigenous healers. Cooperation in the field of mental health in South Africa could be beneficial to people with mental illnesses. Those patients needing control of symptoms could be treated through hospital services and those who could benefit through the intervention of healers should do so. The concept of "Freedom of choice" in relation to the choice of health services should be practically implemented, and not be paid lip-service by the health professionals. For as long as the professional health workers fail to accept the reality of the health siruation in Africa in general and in South Africa in particular, cooperation with the indigenous healers will be theoretical only.

Information in Table 2 suggests that there are healers who possess knowledge of indigenous herbs that control alcohol consumption, which are unknown to formal health workers Exploitation of the knowledge of the medicinal herbs indigenous to Africa as used by the healers would assist a lot in the treatment of alcoholics without hospitalizing them. Such practice would also cut down on the costs of hospital care in a country with scarce economic health care resources.

Fertility is a big problem among young men and women and it is in this problem area that the healers $(91 \%)$ claim great success. This area includes impotence, and the two conditions are a thom in the flesh in that they have got cultural connotations. First, a man must be active sexually, otherwise he is less than a man. Secondly, a woman is expected to bear children, otherwise she is looked upon as a eunuch. Both conditions put one in a position of shame in the eyes of the community. The high figures of participants who deal with this problem and who indicate success in assisting the women to fall pregnant, and in helping men to regain their sexual virility is another indication that needs to be considered.

If the indigenous healers can assist people to bear children, they are of great help in preventing one of the great family disruptions within the black families. Conversely, lack of sexual activity on the par of the man is a source of family disorganization and unfaithfulness. The healer's ability to deal with both conditions is tantamount to prevention of battering and violence within the family, and promotion of health and well-being.

Health is described by the Worid Health Organization as including well-being, and depends on the prevention of diseases and promotion of health by and among the community themselves. Through "go thaya motse" and "go thapisa" (home fortification and cleansing), healers as family practitioners facilitate social well-being in the way acceptable to people they serve.

The findings also point out to their role in promoting economic empowerment within the community. The fact that traders consult them specifically for trading purposes indicates their involvement in keeping businesses successful. Smith (1988 agrees that the most important task of the healer is to protect the community against witches/wizards, to drive away thieves, to keep businesses successful and to promote love relationships.
Health education is not new to Africa. The emphasis on taboos, the prohibition of sex immediately following widowhood and abortion, the use of "Lephakwana" (stick placed at the door of the lying-in room as a sign of isolation of mother and baby), and letting "Mmayabotsetse" (a community maternity helper, usually a family relative, to assist the delivered woman to recuperate) sleep in the same room with the newly delivered woman, are all health educational disease preventive and health promotional activities fostered by indigenous healers. The good of these health activities need to be acknowledged by formal health workers.

Mokhobo (1978:14) acknowledges that "the traditional healer is unquestionably best able to handle ailments at a cultural set up". The author states that the healers have no place in modern medicine, and that "Time will phase them out". This last statement is questionable; for they have been in existence since the African was born on this planet. And since Mokhiobo made this statement seventeen years ago, there does not seem to be any indication that the indigenous healers are being phased out. Instead, national policy demands cooperation with them. Until Eurocentric attitudes such as the one held by Mokhobo are changed, indigenous healers will remain undermined by the Western trained health workers, especially medical practitioners. It is the patient who should dictate terms, no health practitioners.

The findings have shown also that treatment methods such as enema, self induced vomiting and scarification are in use by the indigenous healers. The potential danger inherent in these treatment methods is great. One is not sure of whether in the apprenticeship training of healers there are any rectal anatomy lessons, let alone the effects of the herbal medicines used. It cannot be said with certainty that an assessment is done before an enema is administered, or before vomiting is induced In this day and era of AIDS, one cannot be sure that the blades used for scarification are either new or sterilized

\section{CONCLUSIONS and RECOMMENDATIONS}

Whether the formal health practitioners accept the indigenous healers and cooperate with them in the provision of community health services or not, black patients utilize their services. The indigenous healers provide measures that prevent certain illnesses. They treat diseases that Westem trained health workers in most cases fail to treat successfully. They prevent social conflicts by ritual cleansing and fortifying of homesteads. They put social relations right by performing sacrificial rites for the ancestors so that the spiritual and the human relationships are in harmony. These services are culturally acceptable to the people and are congruent with the people's belief systems. 
It is recommended that the indigenous healers be registered with their association. This move will facilitate location and consultation with the healers in cases of need. It also will make it possible for the healers to be known.

Knowledge of traditional medicine should be exploited to increase knowledge of herbal medicines in the country. This move will help reduce the cost of medicines; and will make medical care affordable to the local communities.

A common platform should be created within the province, where the indigenous healers and formal health workers could discuss issues of common concern and plan health care together. Critical health issues such as those that can cause fatalities and infections should be addressed at platforms without one party undermining the other. This could encourage a relationship of trust between practitioners of the two health systems and help close the communication gap between them. Patients should be free to choose the type of health service they would like to attend without fear on intimidation from the formal health workers. If the patient wants to consult the indigenous healer, he should be allowed to do so and vice versa.

Further research needs to be undertaken to determine other health aspects related to indigenous healing. Traditional African medicines, their chemical composition and their effects need investigation. This can only take place in a collaborative atmosphere with a relationship of openness and trust between the formal health workers and the healers.

\section{ACKNOWLEDGEMENTS}

The efforts of the students who took part in this study are acknowledged and appreciated.

\section{REFERENCES}

Ademuwagun Z. A. (1976): The challenge of the co-existence of orthodox and traditional medicine in Nigeria. The East African Medical Joumal, 53(1): 21-32.

Bryant, A.T. (1983): Zulu medicine and medicine men. Cape Town: Centaur.

Edwards, S.D. (1986): Traditional and modern medicine: A South African research study. Social Science \& Medicine, 22(11): 1273-1276.

Gumede, M.V. (1990): Traditional healers: a medical practitioner's perspective. Johannesburg: Skotaville.

Khumalo, J. (1988): Are inyangas crooks? Pace. June, 7-8.

Koumare, M. (1983): Traditional medicine and opsychiatry in Africa (in Bannerman, $\mathrm{R}, \mathrm{H}$.
Burton, \& Wen-Chie). Traditional medicine and health care coverage. Geneva: WHO.

Lambo, T.A. (1973): Psychotherapy in Africa Psycother Psycosom. 24(13):11-1326.

Mogoba, E.T.M. (1984): Insight into training and functioning of traditional doctors in Southern Africa. A dissertation submitted in compliance with the requirement of M Prax Med Degree of the Department of Family Medicine of the Medical University of Southem Africa.

Mokhobo, K.P. (1978): The African medicine ma and the feasibility for referral. The Leech 48, 14.

Nemec, J. (1980): Re-discovering an ancient resource. Contact, 58, 1-18.

Staugard, F. (1985): Traditional medicine in Botswana. Gaborone: Ipelegeng.

van Rensburg, H.C.G \& Mans (1982). Profile of disease and health care in South Africa. Cape Town: Academia.

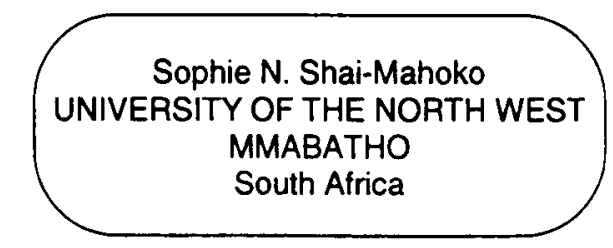

